\title{
Designing Smart Services: A System Dynamics-Based Business Modeling Method for IoT-Enabled Maintenance Services
}

\author{
Henk Akkermans \\ Tilburg University \\ ha@uvt.nl \\ Quan Zhu \\ Tilburg University \\ quanzhu.nju@, \\ gmail.com
}

\author{
Feng Fang \\ Asset Health \\ Dynamics BV \\ feng@assethealth \\ dynamics.com
}

\author{
Laurens Lamper \\ Asset Health \\ Dynamics BV \\ laurens@assethealth \\ dynamics.com
}

\author{
Roland van de Kerkhof \\ Asset Health \\ Dynamics BV \\ roland@assethealth \\ dynamics.com
}

\begin{abstract}
This paper reports on a design science research project aiming to develop a method to support business decision-making regarding IoT-enabled maintenance services for Original Equipment Manufacturers (OEMs). Often, these OEMs remain reluctant to make full use of recent advances in the Internet of Things (IoT), sensor technologies and data analytics for providing services on installed equipment with Asset Owners (AOs). These new developments allow them to advance on their servitization journeys from selling products to selling product-centered services.

The method is based on System dynamics (SD), a powerful modeling methodology to capture all these complexities in an integral, coherent and visible manner with all stakeholders. It also allows for a quantitative analysis of the business case for "smart maintenance services". The paper describes servitization, smart (i.e. digitally enabled) maintenance services and then the method itself. A case study illustrates the application of the method for an OEM in the semiconductor industry.
\end{abstract}

\section{Introduction}

Although Business-to-Consumer (B2C) applications of Internet of Things (IoT) have captured much of the public attention, it is in B2B (Businessto-Business) settings that the biggest business opportunities lie, in combination with sensor technology and data analytics [1]. Here, so-called predictive maintenance typically ranks at the top of business growth markets $[1,2,3]$. This potential is especially large for the Original Equipment Manufacturers (OEMs) who make and sell the complex equipment that is to be maintained more 'smartly', i.e. digitally enabled. $[4,5,6]$. Firstly, because providing such services to Asset Owners creates extra business. Selling 'smart services' as extensions to existing product/service offerings or as new services brings additional revenues. When such data are used for process optimization, this will reduce costs and enhance financial transparency. Secondly, because entering smart service business may create competitive advantages. Using smart solutions such as condition monitoring, early alarms and predictive maintenance can improve efficiency for OEMs. Using data analytics, OEMs can make fast decisions and respond to emerging issues quickly. Finally, because the customer relationship is improved when OEMs become better capable of meeting customer needs and requirements.

However, presently it remains a challenging task for OEMs to make the transition from product providers to smart service providers. There appear to be three interrelated sets of factors that slow down this progress. Firstly, OEMs have to cope with the technical complexity associated with smart services [5]. In order to manage smart and connected products, they have to overcome deficits in technology. Also, the lack of standards and interoperability of data create challenges for OEMs in collecting and transferring the data they need. Issues of data ownership, security and privacy require special attentions. A further challenge in the data analytics needed for smart services remains the scarcity of specialized staff and expertise. Companies experience difficulties in organizing and managing the right human resources effectively and retaining them.

Secondly, in the process of becoming smart service providers OEMs face challenges arising from organizational complexity. Smart service business demands different mindsets and business models 
compared to traditional business. Changing mindsets and business models is not an easy task. It requires a clear vision in dealing with resistance to change internally (as multiple stakeholders have different interests), and in deriving profitable new business models that offer value to customers, despite upfront investments and uncertain Return on Investment (RoI).

Often, the first organizational challenge is to reconcile different interests and perspectives from many internal stakeholders, such as R\&D, Operations, Maintenance, Service, Sales, Finance, Human Resources and IT. The transition from providing products to providing services has different implications for different functions. For instance, what was once a peripheral after-sales service activity increasingly becomes the heart of the business [6]. In addition, as pre-sales involves relationship management, the service engineer obtains a supporting role for the sales force. To support these new smart services, R\&D departments, traditionally focused on product development, is required to work in close partnership with software and data specialists to ensure products that have the right data-delivery capabilities built in. They need to develop products from a Design-for-Maintenance mindset, to ensure that products are durable and serviceable at low cost.

A second organizational challenge is to convince customers and reconcile the different perspectives and interests within those customers. For example, buying smart services is very different from buying products for customers [6]. Buying products is the domain of the purchasing department while buying guaranteed outputs from those products is a matter for operations managers. The discussion on whether to buy "inputs" (products) or "outputs" (guaranteed performance of the products) takes place in the boardroom. The offering and the conversations around it need to resonate with a range of stakeholders, such as the operations director on reliability, the finance director on cost and investment and the technology director on technology integration. It is no longer enough to simply interact with the purchasing director and negotiate the price of a specific item. So the following question needs to be answered to develop a sound business model: How can we develop and price new services that (a) deliver acceptable margins for us as OEMs and (b) are also attractive for our customers? [7].

Many OEMs have become accustomed to using services as a means to negotiate overall product price for years. They are often used to working with cost-plus calculations. Such calculations do not work for smart services [8]. There is often insufficient insight into the cost and benefit aspects of the activities. Customers argue that OEMs also benefit from smart services, through cost reduction and increased flexibility on their side, and through stronger customer lock-in [9].

Thirdly, OEMs encounter challenges because of dynamic complexity: all these interrelations between customer needs and interests of internal stakeholders, installed base and service capacities keep evolving over time. Any static picture is bound to be increasingly incorrect as time passes. Getting the timing right is key in closing the deal on servitized offerings. Once sold, offerings develop over time, reflecting the customer's evolving needs and confidence, and may take on a shape very different to their original form [4].

The move towards servitization requires a significant change in business model. One recent survey found that $75 \%$ of the companies interviewed expect to get a significant portion of their revenue from output- or outcome-based services rather than products in the next three years, $70 \%$ did not have a service strategy in place [6]. Some $80 \%$ had a good level of enabling technology and availability of data, however, they failed to utilize the potential of connecting these capabilities and using them to tap into the customer needs.

This paper does not zoom in on the technical complexities. It focuses on challenges arising from organizational and dynamic complexity. Our aim in this research is to develop a method to support business decisions regarding the introduction of smart maintenance services. This method can be used to develop a business model that is attractive for all affected parties around the table, both the stakeholders within the OEM as those within their AO customers.

\section{Servitization}

The term servitization was first introduced by Vandermerwe and Rada [9]. They defined servitization as "the increased offering of fuller market packages or 'bundles' of customer focused combinations of goods, services, support, self-service and knowledge in order to add value to core product offerings". Later research has established other definitions of servitization, but what remains is a broad consensus on the notion that servitization is a process of building revenue streams for OEMs from services [10]. 


\subsection{Servitization trends}

Servitization has become a global trend among OEMs. Martinez et al. [11] report that over a third of large OEMs worldwide offer services and in developed countries around two out of three of them have started a journey of servitization. A 2017 survey [12] showed that $56 \%$ of OEMs in UK consider themselves as an intermediate or advanced service provider. Research from 2016, which interviewed 60 European OEMs, reported that $85 \%$ of survey participants aimed to deliver output-based services in three to five years, and $75 \%$ of companies expected service to become a significant part of their business in the next three to five years [6].

\subsection{Motivations for servitization}

OEMs have three types of motivations to servitize: competitive motivations, demand-based motivations and economic motivations [5]. Out of competitive motivations, OEMs may provide product related services to ensure the correct functioning of the product. From customer demand-based motivations, they may provide additional services to improve the quality of the buyer-supplier relationship. Economic motivations refer to supporting the operational needs of customers and enabling new revenue streams for OEMs.

AOs' motivations for servitization can also be grouped in three categories [4]. Firstly, AOs seek to combine improved performance of their technical assets, with reduced operating costs and risks. The OEM-led servitization can provide these. Secondly, by outsourcing service activities to the OEMs, AOs can focus their energies and resources on their core business activities. Thirdly, by not buying capital goods but the use of those capital goods, they improve financial transparency and transfer fixed capital costs into variable operational costs.

\subsection{Different levels of servitization}

Servitization can take place at different levels of sophistication, ranging from products with services as an "add-on" to services with tangible goods as an "add-on" [12]. Such sophistication can be broadly categorized into three levels [4]:

1) At the base service level, OEMs offer service focused on product provisions, such as equipment provision, spare part provision, and warranty claims. Services are considered a necessity to support product sales. OEMs compete on their production competences (i.e. "we know how to build it").

2) At the intermediate service level, OEMs provide services with a focus on maintaining product condition. Examples of such services are scheduled maintenance, technical helpdesk, repair, overhaul, delivery to site, operator training, condition monitoring and in-field service. In this stage, services are viewed as added value to customers. OEMs not only exploit their production competences but also maintain the condition of their products (i.e. "because we know how to build it, we know how to repair it").

3 ) At the advanced service level, OEMs offer services to achieve desired outcomes for customers that the technical asset provides through its performance. Here, OEMs view services as their core business. To compete, OEMs translate their production competencies into competence of managing asset performance (i.e. "because we know how to build it, we know how to keep it operational"). Advanced services consist of a complex bundling of product and service offerings. They typically include OEMs revenues from usage, risk and revenue sharing (e.g. performance incentives) as well as long-term contractual agreements (e.g. customer support agreements rental/lease agreements) [1].

The higher the level of service, the more service is used to support customers. The more advanced the servitization level becomes, the higher the potential economic benefits but also the higher the shift of risks and responsibilities for AOs back to OEMs.

\section{Smart services}

\subsection{Defining smart services}

Smart services are defined as data-driven, individually configurable bundles of services, digital applications, and technologies [13]. They are usually delivered via an intelligent object ("smart sensor") that is able to sense its own condition and its surroundings and thus allows for real-time data collection, continuous communication and interactive feedback [7,14]. In general, a smart service has the following characteristics [6]: first, it maintains connections between the physical and the digital world; second, it upgrades value creation and economic efficiency; third, it extends products and services to a digital level; fourth, it transforms a product into a part of a service; fifth, it requires a change from product centered to customer centered business models. 


\subsection{Smart service maturity}

Neuhüttler et al. [13] present a framework showing different maturity levels of smart services OEMs might develop:

The first level is Web-based services, which represents the first effort of manufacturers towards digitalized service offerings. An example of webbased services is a web shop for spare part ordering and providing service reports, contracts and manuals as electronic documents. As web-based services are rather rudimentary versions of smart services, they do not fit all elements of the abovementioned definition.

The second smart service maturity level is Standalone Smart Services. At this level, OEMs begin to provide services based on machine data collected via sensors, transmitted from the $\mathrm{AO}$ environment back to the OEMs and stored in their back-end systems. A well-known example is condition monitoring. Based on the continuous collection and analysis of machine data for conspicuous patterns, OEMs are able to identify anomalies and hence potential failures at an early stage and can conduct preventive maintenance to prevent breakdowns of $\mathrm{AO}$ plants and equipment.

At the smart service maturity level of Smart Service Platforms, OEMs firms offer a wide range of smart services through their company platform. Thanks to a portfolio of data-driven and valueadded applications and services, the stand-alone smart service (e.g. condition monitoring) is advanced to a more integrated smart service. This includes integrated performance cockpits, predictive maintenance solutions, and fleet management systems. In addition to the enhancement of service to customers, the smart service platform is also beneficial to OEMs for internal use.

The fourth smart service maturity level is labeled as Smart Service Industrial Platform. This corresponds with the use of the OEM-specific smart service platform by other smart service providers and ecosystem stakeholder as fully automated electronic market places, where products, services, production capacities or data are traded between suppliers and consumers across company borders.

\subsection{IoT and smart services}

In the present generation of digital innovations, the Internet of Things is really the core distinguishing factor $[14,15]$. More specifically, sensor-driven decision analytics in support of human decisionmaking is now the focus of attention [16]. This only becomes more true in the ear of $5 \mathrm{G}$ mobile communication [17]. Much focus so far has been on IoT business models for multi-sided consumer markets, where also grocers, advertisers and telecom providers play independent roles $[18,19,20]$. In the B2B context of CBM services, there are only 2 or 3 actors: the OEM, the $\mathrm{AO}$ and potentially a maintenance service provider (SP) for the AO.

To successfully become a smart service provider, it is essential for OEMs to closely understand their customers' needs and their surroundings, to have smart data and platforms, to integrate and process these data, and to change the company mindset and business models. Marquardt [21] points out that the prerequisites for smart service are:

1) to develop smart and connected products, which integrate electronic intelligence such as sensors, controllers, microprocessors and data storage chips with wireless internet connection;

2) to have encrypted and secured data collection, transfer and storage;

3) to have data analytics and data-based intelligence for supported decisions and solution finding; and

4) to adopt smart service business models and mindset by using customer-centered and solutionoriented approaches with higher service focus and preemptive acting to avoid unpleasant surprises for customers. Again, the more advanced the smart service OEMs offer, the bigger the distance becomes from their core manufacturing business. And so, the more radical the changes OEMs have to make to their original business model.

\section{Research Method}

\subsection{Design Science Research}

The work reported in this paper is part of a greater Design Science Research (DSR) project. DSR is a prominent form of scholarship in the MIS community, with a long history [22, 23] going back to Herbert Simon's work on the Sciences of the Artificial [24]. The design-science paradigm is fundamentally a problem-solving paradigm. It seeks to create innovations in the form of (IT) artifacts "intended to solve identified organizational problems" [25]. Rather than a research question, this DSR has a research objective [26], which is to develop a method to support decision-making in the introduction of smart maintenance services for OEMs.

\subsection{Case selection}


This paper focuses specifically on the design artifact, not on the design process or on the evaluation of the effectiveness of the artifact. Case studies are used in DSR to improve and test the transferability of the method. In the current paper we present one case study in which an intermediate version of the method was applied to illustrate the method,

This DSR project has been conducted as a business modeling work package within the PROSELO NEXT Research Programme [27], which is an applied research project by four Dutch Universities with leading OEMs on board. It is sponsored by DINALOG, a Dutch government entity. Within the business modeling work package, four case studies were conducted with industrial companies: first an OEM producing complex printing equipment, next an OEM producing semiconductor manufacturing equipment, then a service provider for aerospace maintenance, and finally an OEM producing materials handling equipment.

\subsection{Case study: Smart services in semiconductor manufacturing}

The case we use to illustrate the method is the second one, which was with a semiconductor manufacturing equipment OEM. We will call this semiconductor OEM Lightbeam. This case setting was a very suitable one for our method, since here clearly all the three types of complexity mentioned before were present.
The setting was technically complex, both the customer environment where Lightbeam's systems were bottleneck machines and the machines themselves, which were very advanced pieces of equipment. There was high organizational complexity as multiple departments at Lightbeam were responsible for specific aspects of customer service, but no one had integral responsibility or visibility of the entire service process. And the semiconductor industry, with its relentless pace of innovation and very volatile customer demand, leads to high dynamic complexity as well. So, three indicators for the appropriateness of the method were present. Such technological rules also form part of the DSR methodology [28].

Lightbeam, provides all customer related services, including accommodation and follow-up of scheduled and unscheduled 'downs' respectively. "Down" means a period in which the equipment is inactive, which is very costly for Lightbeam's customers, semiconductor manufacturers. This "down" can either be scheduled (maintenance or inactivity) or unscheduled (failure, damage). Different service levels are established to harmonize goals with the customer. These transitions are illustrated in Figure 1.

\subsection{Design artifact: the Smart Service Cookbook}

We have called our method the Smart Service Cookbook. It is based on a combination of (1) existing business modeling methods, (2) knowledge from the field of industrial maintenance and services and (3) the system dynamics modeling method for managerial decision-making. As such, it is a special form of business modeling.

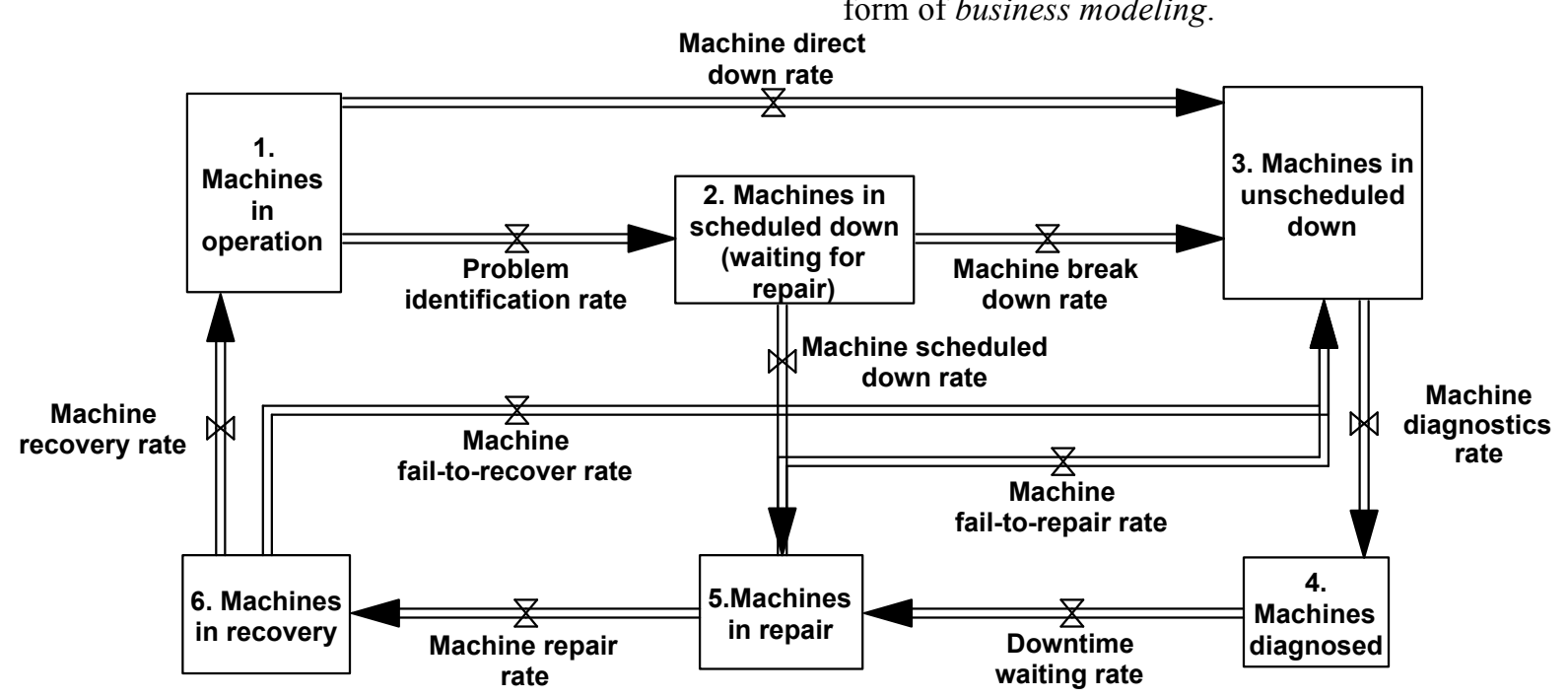

Figure 1: Machine status transitions in Lightbeam case 


\section{Business models and modeling}

\subsection{A Business Model "Canvas" for Services}

A business model has been defined as a description of an organization and how it functions in achieving its goals such as profitability, growth, innovation, social impact and value creation [29]. However, there is a lack of agreement among scholars on more operational definitions of a business model. There are three different interpretations of what a business model is. Business models can be considered as attributes of real firms, as cognitive or linguistic schemas, or as formal conceptual representations of how an organization operates [30]. In this paper, business models are regarded as formal representations of how an organization operates.

There are two fundamental methods to present a business model. The first method offers a flow logic that considers value flows and activities. A prominent example for this is the e3-Value method [30]. The second method offers a system-level holistic view on the business logic of an economic entity or offering. A prominent example is the Business Model Canvas [31]. Here, seven basic building blocks and their interrelations make up a business model canvas. All these elements are logically and causally integrated: (1) Key partners; (2) Strategic resources, (3) Value proposition and Key Performance Indicators, (4) Key processes, (5) Customer segments, (6) Cost structure and (7) Revenue streams.

The business model canvas is a useful framework to represent how a company can operate to achieve its goal in traditional product selling business. The original business model canvas was not aimed towards service business models [32].

Service business models have to be developed with the interests of both customers and service providers in mind. The ability to adapt to changing customer needs is one of the central characteristics of a service business model. The service business model must be able to change over time. OEMs have to adapt it in a flexible manner to specific customer contexts. Achieving value for customers and fulfilling customer demands over the entire life cycle is a central aspect of a service business model. Due to the associated uncertainty and the feedback characteristic in the service life cycle, long-term contracts remain incomplete, since contingencies are often unpredictable. Dealing with uncertainty, in terms of high complexity and dynamism, is therefore one of the key challenges in developing sound service business models. Dynamic business modeling can help to achieve design and development of such models.

\subsection{Dynamic Business Modeling (DBM)}

Using System Dynamics [33, 34] for business model development offers many advantages: SD models are useful for (1) mapping structures of business systems, which helps to understand complex business processes. Their intrinsic feedback loop perspective, in which business systems are viewed as a combination of many closed feedback loops, helps to (2) foster an endogenous and integral business perspective, in which developments are not seen as occurring from outside, so exogenous but from within the business system under study, and so in principle within control of the policy makers in the system [34].

System Dynamics translates a conceptual model of a business system into a quantified simulation model. This formalization and quantification provides a discipline to (3) recognize better the causal interactions over time between the many factors involved [35]. It also helps to (4) recognize complex nonlinear dynamics, such as S-shaped growth, oscillation, tipping points and boom-bust behavior, all of which may occur in the context of smart service development. As such simulation models are usually calibrated against the known performance over time of the KPIs (Key Performance Indicators) of the model, they (5) build confidence in the soundness of the policies that it suggests as most promising. These models allow for policy analysis: After calibration, (6) What-If analysis can be conducted to see how KPIs would change in response to different policies.

(7) Sensitivity analysis can point out under what (normally implicit) assumptions for values of business parameters these policies make sense. In short, the simulations allow managers to discover how complex business systems work and aid in identifying high leverage points $[25,26]$.

System dynamics modeling was used to identify the road towards the most ambitious level of customer service for Lightbeam. Managers from a range of departments were interviewed to gather information, collect data and form assumptions on high-level service practices. Several group modeling building $[38,39]$ sessions were held with interviewees to generate research questions, identify scenarios and to improve and validate the model. It was our second application of our Dynamic Business Modeling method. After the third case, we summarized our findings in a so-called 'Cookbook' for smart services. 


\section{The smart service cookbook}

Our Smart Service Cookbook method describes a Dynamic Business Modeling (DBM) method in the context of smart services. This section explains what the ingredients and steps are to be taken in this method.

\subsection{Team composition}

A common method that is used to develop SD models is Group Model Building [38, 39]. Group Model Building is the assortment of techniques used to develop system dynamics models, collaborating directly with client groups on strategic decisions. To successfully develop dynamic smart service business models, it is essential to have a diverse group modeling team. Participants from different disciplines with varying competences and qualifications can provide different insights that are particularly helpful in the group modeling process. If they are not involved during the model-building process, they will not feel ownership for the model and its recommendations. So implementation of recommendations may become problematic [39].

The natural project composition for modeling engagements consists of at least four stakeholders:

(1) The model project manager (this can be a staff member or managers who want to develop DBMs for smart services; in this case they also act as the project manager, responsible for project planning and progress);

(2) The project sponsor (often someone from higher management);

(3) Line managers and support staff from relevant departments for smart services (e.g. Maintenance, customer support, system engineering etc.);

(4) Key stakeholders from the customer side.

The team members split up in three sub-teams, each with specific qualifications and tasks: a steering team, a reference team and a contact group. The steering team consists of the model project manager and the project sponsor, possibly with the line manager involved whose business is most directly affected. One person can combine the first two roles, provided (s)he has the skills for both tasks. This group convenes only at certain key stages of the project to review the progress and decide the following actions.

The reference group consists of 2-3 managers who are proactive in project design. Whenever the modeler needs to have an informal session with effective decision-making, the reference group convenes. Support staff and the line managers dealing with the front line issues, but not part of the reference group, are within the contact group. They are mostly invited for the group modeling sessions as their in-depth knowledge about parts of the issue from regularly dealing with is extremely useful. In particularly, these line managers are also often crucial for successful implementation of the recommendations.

This is also what we did in the Lightbeam case. One of the authors was the lead investigator and conducted nineteen interviews with key stakeholders from four different departments. This led to a first group model-building session in which the scope of the subsequent analysis was determined.

\subsection{A three-phase approach}

Dynamic business models are developed in three distinct phases:

Stage 1 is the design of dynamic business model, which consists of Scoping and Problem Conceptualization. The aim of this stage is to understand and describe business problems and develop a conceptual model that explains the possible causes of the business problems.

Stage 2 is the DBM Engineering, which consists of Technical Design and Policy Analysis. In this stage, the developed conceptual model from stage 1 is provided with equations and parameter values. In addition, a variety of diagnostic simulations are conducted.

Stage 3 is the dissemination of the knowledge learned from DBM. In this phase, problem insights and recommendations are documented (e.g. final reports and management presentations) and the SD model is transformed with a simulation tool to enable communication of the insights in workshops.

\subsection{Stage 1 DBM design}

DBM design consists of two steps: Scoping and Problem conceptualization. The former focuses on identifying the problem situation, while the latter seeks to map the relevant feedback structure (causal loop diagrams or stock \& flow diagrams) in order to conceptualize business problems.

The scoping phase asks for brainstorming or divergent thinking in order to determine whether factors or variables should be included or excluded from a system's boundary. This can be achieved by 'nominal group techniques, in which brainstorming first takes place individually, after which the individual ideas are discussed and clustered by the 
group. This makes verbal dominancy by a part of the group or group thinking less likely [38]. This phase ends with a well-defined problem definition and a project plan for going forward.

In the next step of problem conceptualization the team uses the business modeling canvas, which serves as a navigation system to make a blueprint of the business model structure. It identifies key strategic trade-offs and options with the reference group. These point to relevant line managers and support staff to form the contact group.

Individual semi-structured interviews with relevant line managers and support staff generate key model elements (relevant variables and parameters), and potential causes of problems (relationships between variables). From these, the modeler develops causal loop- and stock \& flow diagrams. These are tested and improved in a follow-up group modeling session with the reference group and people in the contact group who have been interviewed. This phase can be messy but is crucial. Extensive development of the model without group interaction limits stakeholders' ownership and creativity [31]. Stakeholders' ownership is pivotal in seeing SD models as boundary-objects [38]

Working towards a shared understanding of the problem comes with obstacles. Complementary and competing views from participants need to be understood in order to harmonize all different views and opinions so that a solution for the problem may be found. In this stage, it is fair to say that the quality of the modeling process is as important as the quality of the model itself.

The deliverables in this phase are the conceptual business model and the revised project plan. A feedback workbook can be used in the process to facilitate communication and provide problem insights and preliminary recommendations.

\subsection{Phase 2 DBM engineering}

The next stage of DBM engineering entails a step of technical design, which involves quantitative modeling and simulation in a continuous design, validation and implementation cycle. This work needs a skilled SD modeler with at least one person from reference team who has specific knowledge about the value-oriented solution for the customer specific business model [41]. In this phase, classical system dynamics simulation modeling, mostly in expert mode is conducted. For a while, the quality of the model becomes more important than the quality of the discussion. This was also the way of working in the Lightbeam case. One of the authors was the primary modeler on site with Lightbeam, with offsite feedback from another author with longterm SD modeling expertise.

Relevant quantitative business data are collected through interviews with relevant line managers and staff from contact group. These are used to quantify the conceptual models, where mathematical equations are specified, model parameters are calibrated, and policy scenarios are defined. In the Lightbeam case, this led to several 'data hunting expeditions', as the quantitative data the team found that they needed could be found, but was dispersed throughout the organization and in different formats. Bringing these distributed bits of quantitative evidence to the table in one integrated model was a benefit in itself for Lightbeam.

All these lead to a calibrated and validated simulation model. The core of the simulation model was already shown in Figure 1. The core consisted of three main building blocks: (1) the mechanisms of scheduled and unscheduled downs, (2) the uptime percentage calculations and (3) the bonus/malus calculation.

Figure 1 illustrates the first building block. Lightbeam staff identified six different states in which machines could be found: (1) in operation, (2) in scheduled down (3) unscheduled down, (4) diagnosed (but not yet repaired), (5) in repair and (6) in recovery (bringing the machine back in full production mode). Each of these states had its own quantified levels rates of change, durations and costs, and data analyses underlying these numbers.

The next stage in DBM Engineering is Policy analysis, where the quality of the modeling process and the model are of equal importance. In an iterative process, better and better policies are designed, tested and individual. One-on-one interviews continue, but a group policy analysis session is required to define the preferred policies collectively with all stakeholders. Advanced mathematical techniques such as sensitivity analyses and even optimizations are appropriate in this stage.

At Lightbeam, only the Machines in Operations stage adds to the uptime percentage, which is crucial for customers. From there, a bonus/malus calculation can be derived. Lightbeam draws up agreements with its customers on the guaranteed service level. If the uptime exceeds the guaranteed service level, Lightbeam will receive increased payments. When the uptime dips below the guaranteed service level, Lightbeam will have to reimburse the customer.

Six different scenarios were developed and tested with the Lightbeam project team to identify what policies would improve both productivity and predictability most. Each of these scenarios affected different flow rates in the model. In the end, policy 
analysis revealed a combination of multiple scenarios as most desirable. However, upon closer scrutiny that scenario worked in the model but was not feasible in the business. Therefore, another slightly less ambitious policy combination was selected, which also led to significant uptime increases and to somewhat lower costs. This illustrates how important it is to navigate back and forth between business simulation model and everyday business reality.

\subsection{Phase 3. DBM dissemination}

After Phase 2, the stakeholders who were involved in the development of the model should feel high ownership of this model. However, that is only a small subset of all the people involved. Communicating the findings in a language without simulation jargon to the broader organization becomes key for implementation.

Management presentations and formal reporting are appropriate here, but also a so-called microworld version of the model can be very powerful to disseminate insights. Technical advances in simulation packages make it possible to run such a simplified version of the simulation models simply in an internet browser, without specialized hardware or software requirements. This makes dissemination of the insights gained by the project team with others in the organization much easier.

\section{Conclusion}

The present digitization of industry provides unique opportunities for our society to make our equipment more reliable, better-performing, sustainable and "greener". Given the way in which our industrial ecosystems are organized, this calls for integrated collaborations between OEMs and their customers, AOs. Such collaboration will not happen without sound business cases, agreed upon by all stakeholders and based on sound quantitative analyses.

This paper describes an ongoing effort to develop a method that facilitates this collaboration process. It could be seen as ironic that a modeling approach such as System Dynamics, which was developed some sixty years ago, helps to innovate such a young and immature business activity as "smart services". Then again, the great cooks also always know their classics.

\section{References}

[1] Manyika, J. Chui, M.. Bisson, P., Woetzel, J., Dobbs, R. Bughin, J., Aharon D. "The Internet of Things: Mapping Value Beyond the Hype", McKinsey Global Institute, 2015.

[2] Bain Company: "Explore the B2B opportunities for IoT vendors", Accessed at http://www2.bain.com/bainweb/media/interactive/IoTopportunities/index.html on August 29, 2018.

[3] Biztech Staff, "The Internet of Things Creates Business Opportunities and Challenges". Biztech Magazine Dec 9, 2016 Accessed at https://biztechmagazine.com/article/2016/12/internetthings-creates-business-opportunities-and-challenges on August 29, 2018.

[4] Baines, T., \& Lightfoot, H. W. "Servitization of the manufacturing firm: Exploring the operations practices and technologies that deliver advanced services". International Journal of Operation \& Production Management, 34(1), 2013, pp. 2-35.

[5] Raddats, C., Baines, T., Burton, J., Story, V. M., \& Zolkiewski, J., "Motivations for servitization: the impact of product complexity", International Journal of Operations \& Production Management, 36(5), 2016, pp. 572-591.

[6] PA Consulting. (2017). "From Products To Services", PA Consulting.

[7] Wünderlich, N. V., Heinonen, K., Ostrom, A. L., Patricio, L., Sousa, R., Voss, C., "Futurizing" smart service: implications for service researchers and managers", Journal of Services Marketing, 29(6), 2015, pp. 442-447.

[8] Parida, V., Sjödin, D. R., Wincent, J., \& Kohtamäki, M., "Mastering the transition to product-service provision: Insights into business models, learning activities, and capabilities", Research-Technology Management, 57(3), 2014, pp. 44-52.

[9] Vandermerwe, S., Rada, J., "Servitization of business: adding value by adding services", European Management Journal 6(3), 1988 pp. 14-324.

[10] Baines, T., Ziaee Bigdeli, A., Bustinza, O. F., Guang Shi, V., Baldwin, J., \& Ridgway, K. "Servitization: Revisiting the State-of-the-art ad Research Priorities", International Journal of Operations \& Production Management. 37(2), 2017, pp. 256-278.

[11] Martinez, V., Neely, A., Velu, C., Leinster-Evans, S., \& Bisessar, D., "Exploring the journey to services". International Journal of Production Economics, 192. 2017, pp. 66-80.

[12] Lightfoot, H. W., Baines, T., \& Smart, P., "The servitization of manufacturing: A systematic literature 
review of interdependent trends", International Journal of Operations \& Production Management, 2013, pp. 14081434.

[13] Neuhüttler, J., Woyke, I. C., \& Ganz, W., "Applying Value Proposition Design for Developing Smart Service Business Models in Manufacturing Firms". International Conference on Applied Human Factors and Ergonomics, 2017, pp. 103-114. Springer.

[14] Fleisch, E., Weinberger, M., "Business Models and the Internet of Things", Bosch IoT Lab White Paper, www.iot-lab.ch, 2014.

[15] Allmendinger, G. and Lombreglia, R., "Four strategies for the age of smart services", Harvard Business Review, 83(10), 2005, pp. 131-145.

[16] Chui, M. Löffler, M. Roberts, R. "The Internet of Things", McKinsey Quarterly March 2010.

[17] Palattella, M.R., Dohler, M. Grieco, A. S Rizzo, G., Torsner, J., Engel, Th., Ladid, L. "Internet of Things in the 5G Era: Enablers, Architecture and Business Models", IEEE Journal on Selected Areas in Communications 34(3) March 2016.

[18] Keshkin, T., Kennedy, D, "Strategies in Smart Service Systems Enabled Multi-Sided Markets: Business Models for the Internet of Things", HICSS Proceedings, 2015, pp. 1444-1542.

[19] Dijkman, R.M., Sprenkels, B. Peeters, T. Janssen, A. "Business models for the Internet of Things", International Journal of Information Management 35, 2015, pp. 672-678.

[20] Chan, H.C.Y., "Internet of Things Business Models", Journal of Service Science and Management, 2015, 8, pp. 552-568.

[21] Marquardt, K. (2017). "Smart services - characteristics, challenges, opportunities and business models. International Conference on Business Excellence", Proceedings of the International Conference on Business Excellence 11(1), 2017, pp. 789-801.

[22] March, S. T., and Smith, G., "Design and Natural Science Research on Information Technology", Decision Support Systems 15 (4), 1995, 251-266.

[23] Markus, M. L., Majchrzak, A., and Gasser, L. 2002. A Design Theory for Systems that Support Emergent Knowledge Processes, MIS Quarterly 26 (3), 179-212.

[24] Simon, H. A. "The Sciences of the Artificial" (3rd ed.), MIT Press, Cambridge, MA, 1996.

[25] Hevner, A.R., March, S.T., Park, J., Ram, S., Design science in information systems research. MIS Quarterly 28(1), 2004, pp. 75-105.
[26] March, S.T., Storey, V.C. 2008. Design science in the Information Systems discipline: An introduction to the special issue on design science research. MIS Quarterly 32(4), 725-730.

[27] https://www.dinalog.nl/project/pro-active-servicelogistics-for-capital-goods-the-next-steps-proselonext.

[28] Van Aken, J.E., "Management research on the basis of the design paradigm: the quest for field-tested and grounded technological rules", Journal of Management Studies, 41(2), 2004, pp. 219-246.

[29] Cosenz, F., and Noto, G. "A dynamic business modelling approach to design and experiment new business venture strategies" Long Range Planning, 2018, pp. 127140.

[30] Massa, L., Tucci, C. I., \& Afuah, A. "A Critical Assessment of Business Model Research", Academy of Management Annals, 2017, pp. 73-104.

[31] Osterwalder, A. "The Business Model Ontology - A Proposition In a Design Science Approach", 2004, Lausanne: University of Lausanne.

[32] Zolnowski, A., Weiß, C., \& Böhmann, T. "Representing Service Business Models with the Service Business Model Canvas - The Case of a Mobile Payment Service in the Retail Industry". International Conference on System Science, 2014, Hawaii, IEEE, pp. 718-727.

[33] Forrester, J. W. "Industrial Dynamics". 1961, Cambridge, MA, MIT Press.

[34] Sterman, J. D. "Business Dynamics", 2000, McGrawHill, London

[35] Davis, J., Eisenhardt, K., \& Bingham, C. "Developing theory through simulation methods", Academy of Management Review, 2017, 480-499.

[36] Richmond, B. "The strategic forum: aligning objectives, strategy and process", System Dynamics Review 13(2), 1997, 131-148.

[37] Warren, K., "Strategic Management Dynamics. Chichester", 2008, Wiley, Chichester

[38] Vennix, J., "Group Model Building: facilitating Team Learning Using System Dynamics", 1996, Wiley Chichester.

[39] Akkermans, H. A. \& Vennix, J. A. M. "Clients' opinions on group model-building: An exploratory study", System Dynamics Review. 13(1), 1997, pp. 3-31. 